\title{
Transdermal physostigmine-absence of effect on topographic brain mapping
}

\author{
M.Y. Neufeld, F. Mawassi, A. Levy', T.A. Treves and A.D. Korczyn \\ Department of Neurology, Tel-Aviv Sourasky Medical Center and Sackler School \\ of Medicine, and ${ }^{1 / s r a e l ~ I n s t i t u t e ~ f o r ~ B i o l o g i c a l ~ R e s e a r c h, ~ N e s s ~ Z i o n a, ~ I s r a e l ~}$ \\ Correspondence to: M.Y. Neufeld, Department of Neurology, Tel-Aviv Sourasky \\ Medical Center, 6 Weizmann Street, Tel-Aviv 64239, Israel
}

\begin{abstract}
Nine patients with primary degenerative dementia (PDD) participated in an open trial of transdermal physostigmine (TPh). In order to evaluate the neurophysiologic effects of TPh, EEG data were recorded and compared at baseline and following 2 months of continuous treatment. There was no significant effect of TPh on EEG spectra in patients with PDD.
\end{abstract}

Keywords: Alzheimer's disease - Brain mapping - Dementia - EEG - Physostigmine

\section{INTRODUCTION}

While the etiology and basic pathogenesis of Alzheimer's disease (AD) are unknown, cholinergic deficiency may underlie some of the manifestations of the disease. It was shown that the levels of the acetylcholine synthesizing enzyme, choline acetyltransferase, are reduced in the brains of patients with $\mathrm{AD}$ (Bartus et al., 1982). Based on these abnormalities in the cholinergic system, a variety of pharmacological approaches have been undertaken in the treatment of $\mathrm{AD}$, most importantly the inhibition of the enzyme acetylcholinesterase (AChE) using several drugs, particularly physostigmine, administered intravenously (Davis and Mohs, 1982). Because of the limitations of the intravenous route, a transdermal system for continuous release of physostigmine (TPh) was developed at the Israel Institute for Biological Research (Levy et al., 1989) and tested in a group of patients, some of whom reported improved vigilance and concentration and had higher scores on neuropsychological memory tests.

In order to evaluate the neurophysiologic effects of TPh on EEG activity we performed topographic brain mapping in patients with primary degenerative dementia prior to and following 2 months of this treatment.

\section{METHODS}

Nine patients (five male, four female), ages ranging from 65 to 84 years (mean \pm S.D., $73.7 \pm 1.7$ years), diagnosed as suffering from $\mathrm{AD}$ according to NINCDS-ADRDA criteria (McKhann et al., 1984) were included. Medical conditions known to produce dementia were excluded by appropriate laboratory tests (SMAC-12, thyroid functions, VDRL, serum B12 levels, and CT of the brain).

Transdermal pads containing $700 \mu$ l of $20 \%$ physostigmine solution in an enhancer vehicle (Levy et al., 1989) were attached to the inner aspect of the patients' arms. The pads were replaced every 3 days. The patients were first hospitalized for 2 weeks and subsequently continued treatment at home with follow-up in the outpatient memory clinic. Neuropsychological tests included two psychogeriatric tests-Mini Mental State Examination (MMSE) (Folstein et al., 1975) and Short Mental Test (SMT) (Treves et al., 1990), and two psychometric-cognitive tests-the Wechsler Memory Scale (WMS) (Wechsler, 1945) and Buschke's Selective Reminding Test (SRT) (Buschke, 1973). Testing was carried out prior to commencement of treatment and 2 months later. Inhibition of AChE in the whole blood was determined. Plasma physostigmine concentration was relatively stable during the study $(0.56 \pm 0.1 \mathrm{ng} / \mathrm{ml})$ and correlated well with blood acetylcholinesterase inhibition.

EEG was recorded on an 18 channel Grass machine model 8, which was connected to a Brain Atlas Bio-logic commercial computer system with data acquisition and field mapping capabilities for 21 electrodes. Disk electrodes were applied to the scalp with collodion in accordance with the international 10-20 system. EEG data were acquired using referential linked ear montage. Signals were filtered with $1 \mathrm{~Hz}$ high pass, $35 \mathrm{~Hz}$ low pass, and $60 \mathrm{~Hz}$ notch filters and digitized at 128 samples per second. During the recordings the patients were instructed 
to remain relaxed yet alert. The EEG was recorded with eyes closed and eyes open. During the eyes open portions, patients were told to fix their gaze on a particular point on the wall and try to inhibit ocular movements. Two min of EEG with eyes open and 2 min with eyes closed were subsequently investigated with the EEG analysis section of the computer system, which allows visual inspection of the EEG traces in real time on a color monitor. Portions of the record containing eye, muscle, and movement artefacts were excluded from further analysis.

A fast Fourier transformation was applied on 16 samples of $2 \mathrm{~s}$ epoch artefact-free EEG, for both eyes open and eyes closed, and averaged. In a second analysis, we recomputed all EEG leads based on the digital computer averaged reference and repeated the spectral analysis in exactly the same way. Frequency spectra were calculated from 18 electrode values, whereas values under Fp1, Fp2, and Fpz electrodes were interpolated. The transformation yielded a value representing the magnitude expressed in microvolts (square root of power). Appropriate coloration produced a clear visual representation of electrical activity. Five EEG bands from 0.5 to $32 \mathrm{~Hz}$ were visualized: delta $(0.5-3.5 \mathrm{~Hz})$, theta $(4-7.5 \mathrm{~Hz})$, alpha $(8-11.5 \mathrm{~Hz})$, beta $1(12-15.5)$ and beta $2(15.5-32 \mathrm{~Hz})$.

The comparison between the five frequency bands of EEG performed before and following treatment with TPh involved the construction of significance probability maps (SPMs), which allow topographic mapping of a statistic that delineates regions of maximal group separation between the subjects' groupings, a form of exploratory analysis (Duffy et al., 1981).

Visual analysis of raw EEG before and following treatment was also performed by an independent electroencephalographer, who was blinded to the patients' diagnoses.

\section{RESULTS}

In the present study $50 \%$ of the patients involved reported improved vigilance and concentration; they also improved their scores in all four neurobehavioral psychological tests employed (submitted for publication). On visual inspection, comparing the EEG of patients prior to and following 2 months of TPh treatment, in three patients no change was observed, in two patients less alpha activity was noted, in two there was mild increase of delta activity and in two mild decrease of delta activity was observed. Delta, theta, alpha and beta maps were visualized for the patients before and after treatment with TPh. The exploratory analysis of EEG, comparing the patients prior to and following treatment led to the formation of 10 SPMs of the five frequency bands tested with eyes open and eyes closed. Inspection of the 10 SPMs revealed no evidence of regional differences between groups. Also in a separate exploratory analysis of an additional 10 SPMs (five frequency bands with eyes closed and eyes open) comparing the group of patients that improved on neuropsychological tests to the one with no improvement, no evidence of between-group regional differences was apparent.

\section{DISCUSSION}

The involvement of cholinergic mechanisms in cortical activation has long been implicated (Detari and Vandervolf, 1987). Studies have demonstrated that the cholinergic nucleus basalis might mediate the effects of cholinergic drugs on neocortical EEG activity (Levey et $a l .$, 1987). To study the effects of agents stimulating cholinergic neurotransmission a widely used pharmacological strategy is to prevent the breakdown of acetylcholine by systemic administration of anticholinesterase drugs such as tetrahydroaminoacridine or physostigmine (Riekkinen et al., 1991).

Most clinical studies of cholinomimetics have relied on neurologic, psychiatric and psychological evaluations (Davis and Mohs, 1982; Harrell et al., 1990); neurophysiologic tests have been used less often and provided inconsistent results (Pfeiffer et al., 1963; Sitaram et al., 1976; Pfefferbaum et al., 1979). Studies of the EEG effects induced by cholinergic drugs report increase in fast frequencies (Pfeiffer et al., 1963), and increased arousal (Sitaram et al., 1976). In a different study using normal volunteers, small doses of intravenous physostigmine revealed few EEG changes as measured by spectral analysis, while administration of larger doses resulted in an increase in the amount of slow frequency activity, and might have reflected a general toxic response (Pfefferbaum et al., 1979). Also no measurable EEG response to choline was observed following oral administration (Pfefferbaum et al., 1979).

EEG activity in AD patients was shown to be associated with increased slowing (Rae-Grant et al., 1987). Deafferentation of the cortex from cholinergic inputs may condition the appearance of cortical delta activity, thus supporting the inversive relationship between cholinergic involvement and delta activity (Detari and Vandervolf, 1987; Levey et al., 1987). Acute effects of intravenous physostigmine treatment were tested in AD patients (Gustafson et al., 1987) and have shown that infusion of physostigmine decreased the relative delta power over the left hemisphere.

In our study measurable EEG response following TPh treatment was absent. Although some of our patients improved clinically, no association was found between clinical response and changes in EEG activity. These data suggest that TPh in the specific route administered, and in the dose and duration employed in this study fails to produce a change in the EEG of the patients with AD. A nega- 
tive result cannot be used to prove that physostigmine does not produce an increase in brain cholinergic function, it merely may imply a lack of effect on overall brain function or limited sensitivity of brain mapping to detect such changes.

\section{REFERENCES}

Bartus R, Dean RL, Bernard B and Lippa AS (1982) The cholinergic hypothesis of geriatric memory dysfunction. Science, 27, 408-418.

Buschke $\mathrm{H}$ (1973) Selective reminding for analysis of memory and learning. Journal of Verbal Learning and Verbal Behaviour, 12, 543-550.

Davis KL and Mohs RC (1982) Enhancement of the memory processes in Alzheimer's disease with multiple-dose intravenous physostigmine. American Journal of Psychiatry, 139, 1421-1424.

Detari L and Vandervolf CH (1987) Activity of cortically projecting and other basal forebrain neurons during large slow waves and cortical activation in anesthetized cat. Brain Research, 437, 1-10.

Duffy FH, Bartels PH and Burchfiel JL (1981) Significance probability mapping: an aid in topographic analysis of brain electrical activity. Electroencephalography and Clinical Neurophysiology, 51, 455-462.

Folstein MF, Folstein SE and Mcttugh PR (1975) "Mini mental state", a practical method for grading the cognitive state of patients for the clinician. Journal of Psychiatric Research, 12, 189-193.

Gustafson L, Edvinsson L, Dahlgren N, Hagberg B, Risberg J, Rosen I and Ferno H (1987) Intravenous physostigmine treatment of Alzheimer's disease evaluated by psychometric testing regional blood flow (rCBF) measurement, and EEG. Psychopharmacology, 93, 31-35.

Harrell LE, Callaway R, Morere D and Falgout J (1990) The effect of long term physostigmine administration in Alzheimer's disease. Neurology, 40, 1350-1354.

Levey AI, Hallanger AE and Wainer BH (1987) Cholinergic nucleus basalis neurons may influence the cortex via the thalamus. Neuroscience Letters, 74, 7-13.

Levy D, Meshulam Y, Grunwald J, Bruckstein R and Levy A (1989) A long acting transdermal system for the treatment of organosphosphate poisoning. Proc.3rd Int. Symp. Protection against Chemical Warfare Agents, Vmea, Sweden, 11-16 June, pp. 151-156. See also Israeli patent 72684 .

McKhann G, Drachman D, Folstein M, Katzman R, Price D and Stadlan EM (1984) Clinical diagnosis of Alzheimer's disease. Neurology, 34, 939-944.

Pfefferbaum A, Davis KL, Coulter CL, Mohs RC, Tinkleberg JR and Kopell BS (1979) EEG effects of physostigmine and choline chloride in humans. Psychopharmacology, 62, 225-233.

Pfeiffer CA, Goldstein L, Munoz C, Murphree HB and Jenny EJ (1963) Quantitative comparison of the electroencephalographic stimulant effects of deanol, choline, and amphetamine. Clinical Pharmacology and Therapeutics, 4, 461-466.

Rae-Grant A, Blume W, Lan C, Hachinski VC and Merskey H (1987) The electroencephalogram in Alzheimer-type dementia. Archives of Neurology, 44, 50-54.

Riekkinen P, Buzsaki G, Riekkinen Jr P, Soininen H and Partanen J (1991) The cholinergic system and EEG slow waves. Electroencephalography and Clinical Neurophysiology, 78, 89-96.

Sitaram M, Wyatt RJ, Dawson S and Gilin JC (1976) REM sleep induction by physostigmine during sleep. Science, 191, 1281-1282.

Treves AT, Rogolsky M and Korczyn AD (1990) Evaluation of short mental test for the diagnosis of dementia. Dementia, 1 , 102-107.

Wechsler D (1945). A standardized memory scale for clinical use. Journal of Psychology, 19, 87-95.

(Received 1 March 1993; accepted 16 March 1993) 


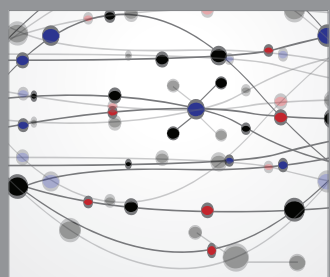

The Scientific World Journal
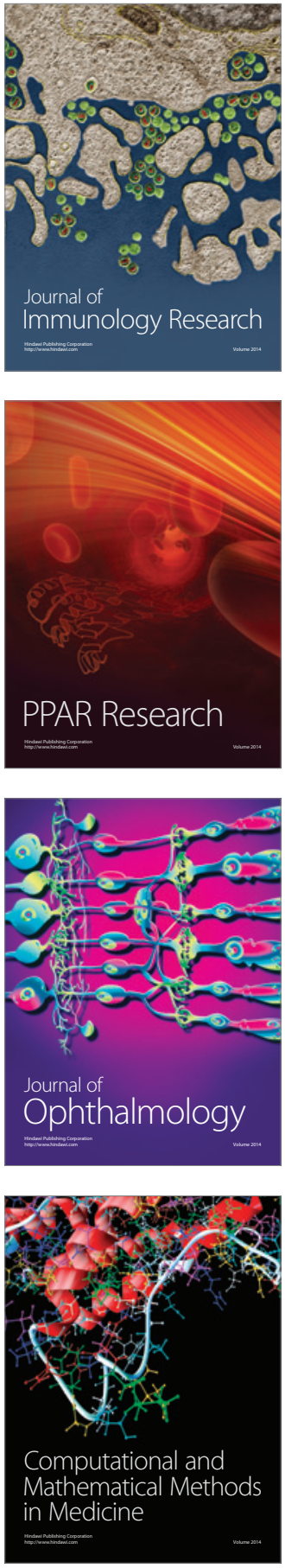

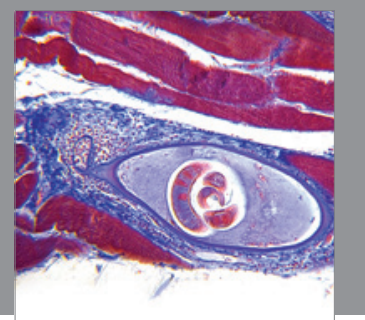

Gastroenterology

Research and Practice
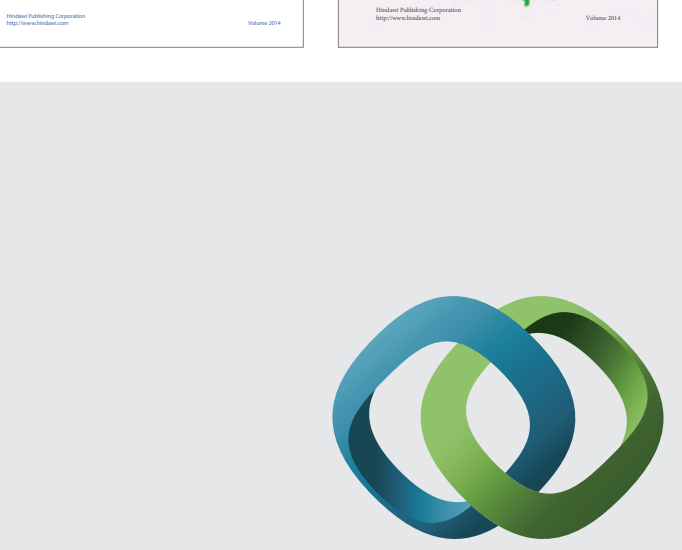

\section{Hindawi}

Submit your manuscripts at

http://www.hindawi.com
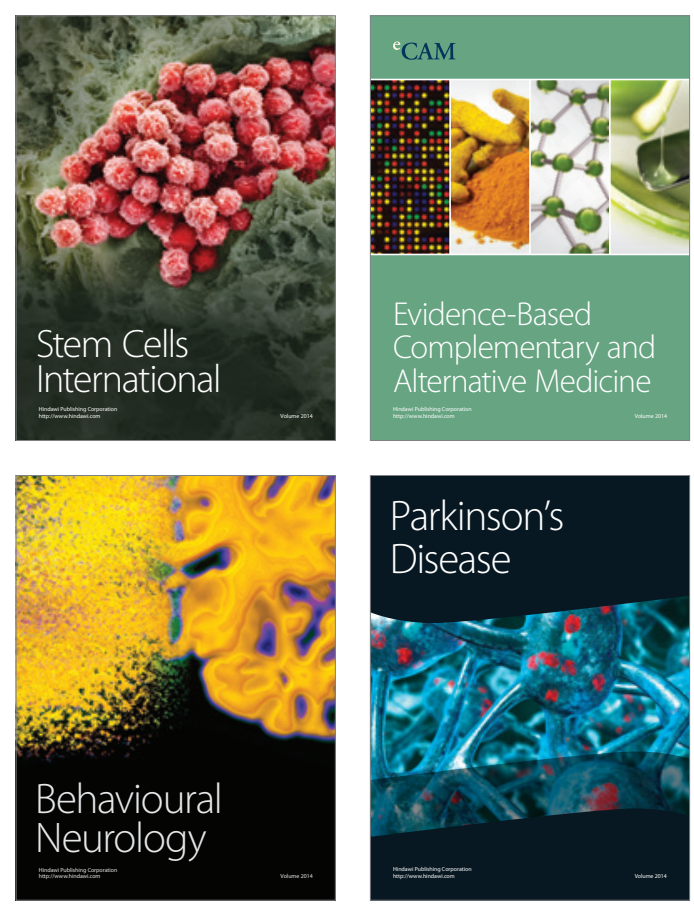

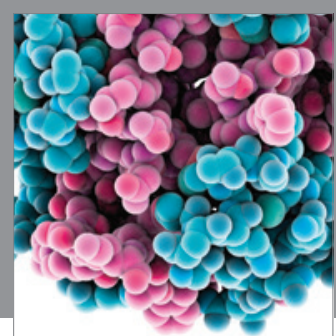

Journal of
Diabetes Research

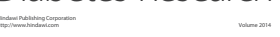

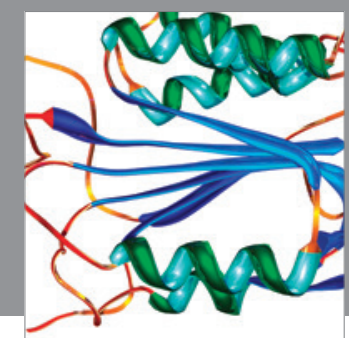

Disease Markers
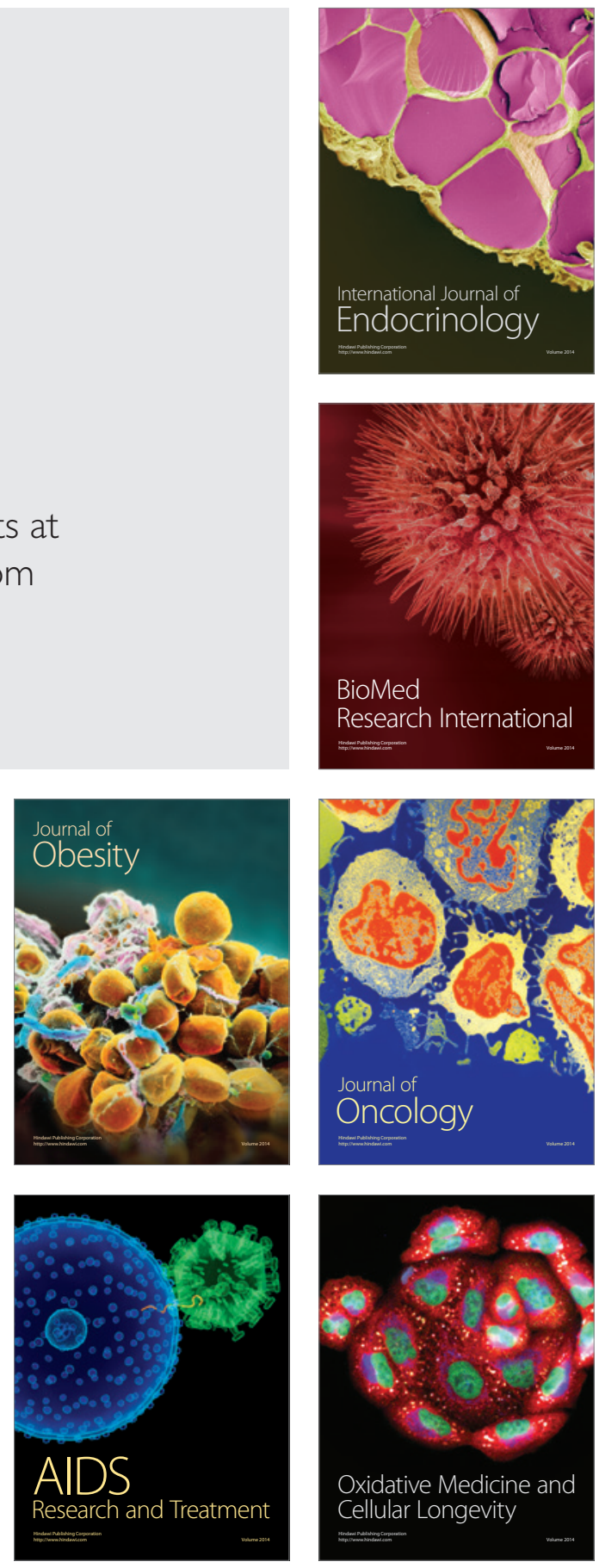